\title{
Effect of ethanol upon gastric emptying
}

\author{
S. E. KAUFMAN AND M. D. KAYE ${ }^{1}$ \\ From The Department of Medicine, University of Vermont College of Medicine, Burlington, Vermont, USA
}

SUMMARY The effect of ethanol upon gastric emptying in healthy human subjects was studied by measuring the gastric emptying rates of three $750 \mathrm{ml}$ meals, the osmolalities, energy densities, and $\mathrm{pH}$ of which were similar. Meal A, which contained $80 \mathrm{ml}$ alcohol, emptied more rapidly than meal $\mathrm{B}$, which contained $40 \mathrm{ml}$ ethanol and $63.3 \mathrm{~g}$ dextrose; and meal B emptied more rapidly than meal $\mathrm{C}$, which contained $126.6 \mathrm{~g}$ dextrose but no ethanol. The slower rate of emptying of the dextrose meal (C) was not due to an increased gastric secretory rate, as serial measurements of gastric $\mathrm{pH}$ were substantially and significantly higher with this than with the other two meals; nor was it due to a greater degree of duodenogastric reflux, as serial measurements of gastric bile acid concentrations were similar for the three meals. We conclude that the duodenal osmoreceptor mechanism is relatively insensitive to ethanol; that the relationship between energy density and gastric emptying rate does not hold in the case of ethanol; and that the gastro-oesophageal reflux which occurs in response to ethanol is not due to impairment of gastric emptying.

Recently we reported that alcohol induces gastrooesophageal reflux in healthy individuals (Kaufman and Kaye, 1978). Possible causes for this effect of alcohol include an adverse effect upon competence of the lower oesophageal sphincter-a possibility supported by the manometric observations of Hogan et al. (1972)-increase in the rate of gastric acid secretion, and slowing of gastric emptying. In this study, we examined the effect of alcohol upon gastric emptying. Hitherto, this facet of the gastrointestinal response to alcohol has received little attention.

\section{Methods}

Ten healthy subjects, eight male and two female, with ages ranging between 20 and 33 years (mean 24.4 years) were studied. Each gave written consent. Subjects selected were free of gastrointestinal symptoms and had no history of upper gastrointestinal disease or surgery. Gastric emptying was studied in each subject on three separate occasions at least 48 hours apart. The composition of the test meals was different for the three studies, but study procedures were similar in all other respects. Alcohol was proscribed for 48 hours before each study, and smoking on the morning of study.

The three test meals were designed to have similar osmolalities, caloric contents and pH. Each had a

${ }^{1}$ Address for correspondence and reprint requests: Michael D. Kaye, C307 Given Building, University of Vermont College of Medicine, Burlington, Vermont 05401, USA.

Received for publication 13 February 1979 volume of $750 \mathrm{ml}$. The chief constituents of meals A and $C$ were ethanol and dextrose respectively. Meal B contained a mixture of ethanol and dextrose. Osmolalities were adjusted by addition of $\mathrm{NaCl}$ and $\mathrm{pH}$ was adjusted to 7 by addition of small quantities of sodium hydroxide or $\mathrm{HCl}$. Osmolalities were measured by freezing point depression on an Osmette osmometer (Precision Systems, Framingham, Mass.). The composition of the meals is shown in the Table.

Table Composition of three test meals

\begin{tabular}{llrrll}
\hline $\begin{array}{l}\text { Test } \\
\text { meal }\end{array}$ & $\begin{array}{l}\text { Ethanol } \\
(\mathrm{m} l)\end{array}$ & $\begin{array}{l}\text { Dextrose } \\
(\mathrm{g})\end{array}$ & $\begin{array}{l}\mathrm{NaCL} \\
(\mathrm{g})\end{array}$ & Mosmol/l & Calories \\
\hline A & 80 & 0 & 0 & 2175 & 508 \\
$\mathrm{~B}$ & 40 & $63 \cdot 3$ & $1 \cdot 5$ & 2185 & $507 \cdot 2$ \\
$\mathrm{C}$ & 0 & $126 \cdot 6$ & $9 \cdot 0$ & 2170 & $506 \cdot 4$ \\
\hline
\end{tabular}

Each test meal had a volume of $750 \mathrm{ml}$ and $\mathrm{pH}$ of 7 .

The method is based upon that described by George (1968). After an overnight fast, a 14 French Salem sump tube was passed through the mouth into the stomach, and its tip positioned between 50 and $55 \mathrm{~cm}$ from the incisors. Fasting gastric juice was aspirated and retained. The position of the tube was checked by ensuring that at least $45 \mathrm{ml}$ of a $50 \mathrm{ml}$ volume of saline instilled through it could be aspirated. The tube was taped in position and the test meal instilled into the stomach by gravity drainage over a period of approximately three minutes. The order of administration of the three meals was 688 
randomised. For 90 minutes after the test meal was introduced (time 0 ), and at 15 minute intervals, $5 \mathrm{ml}$ samples of gastric contents were aspirated. After each aspiration, $10 \mathrm{ml}$ phenol red solution $(0.5 \mathrm{mg}$ per $\mathrm{ml}$ ) were transferred by pipette into a syringe from which the plunger had been withdrawn, and injected into the stomach through the tube. Mixing was achieved by serial aspiration and injection of gastric contents and by rocking motions of the supine subjects. One minute after injection of the phenol red, a second $5 \mathrm{ml}$ sample of gastric contents was removed. At the end of the 90 minute study period, the stomach was emptied by aspiration and the residual volume recorded.

$\mathrm{pH}$ was measured by means of glass electrode and a radiometer PHM $62 \mathrm{pH}$ meter on samples obtained at times $0,15,30,45,60,75$, and 90 minutes.

Phenol red concentration was measured in samples obtained at times $15,30,45,60,75$, and 90 minutes. After centrifugation to remove mucus, a $0.5 \mathrm{ml}$ aliquot of the gastric sample was added to $2.5 \mathrm{ml}$ of a tri-sodium phosphate buffer solution $(27.5 \mathrm{~g} / \mathrm{l})$ and the mixture made up to $10 \mathrm{ml}$ with distilled water. The optical density developed was measured at $560 \mathrm{~m} \mu$ on a Gilson spectrophotometer. Phenol red concentrations were determined by reference to a standard curve.

The volume remaining at a given point in time was obtained from the formula $V_{1}=V_{2}\left(C_{2}-C_{3}\right) /$ $C_{3}-C_{1}$, where $V_{1}$ is volume remaining, $V_{2}$ is the volume of marker added to $V_{1}, C_{1}$ is the initial concentration of marker in $V_{1}, C_{2}$ is the concentration of the added marker, and $C_{3}$ is the final concentration of the mixture.

To estimate duodenogastric reflux in response to the different meals, gastric concentrations of glycocholic acid and glycochenodeoxycholic acid were measured by radioimmunoassays specific for these bile acids (Demers and Hepner, 1976; Simmonds $\epsilon t$ al., 1973) in samples obtained at times $0,30,60$, and 90 minutes.

Blood ethanol concentrations were measured spectrophotometrically by a method based upon that described by Bonnichsen and Theorell (1951) in blood samples obtained at times $15,30,45,60,75$, and 90 minutes, on days when the test meal administered contained ethanol (meals A and B).

\section{Results}

In nine of the 10 subjects, satisfactory curves for gastric emptying were obtained. In one, who was somewhat uncooperative, adequate mixing of gastric contents after phenol red injection could not be achieved, and the curves were erratic. The data from this subject have been excluded. The results described pertain to the remaining nine subjects.

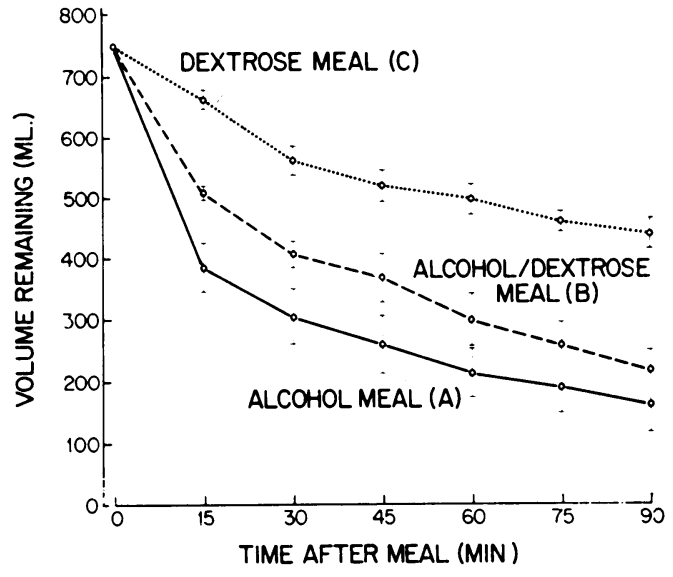

Fig. 1 Gastric emptying of the three meals. Each point represents the mean and standard error of the mean for nine subjects. The significance of differences is indicated in the text.

\section{GASTRIC EMPTYING}

Curves depicting emptying of the three meals are shown in Fig. 1. The dextrose meal (C) emptied much more slowly than the ethanol-dextrose meal (B), which in turn emptied more slowly than the ethanol meal (A). Differences between meals $A$ and $C$, and $B$ and $C$ were statistically significant $(P<0 \cdot 01$, Wilcoxon's rank sum test, two tailed) at all time points. Differences between meals $\mathrm{A}$ and $\mathrm{B}$ were statistically significant $(P<0.05)$ at 15,30 , and 45 minutes. At subsequent time points, the differences failed to reach statistical significance $(P>0.05)$. From a semi-logarithmic plot (Fig. 2), it is apparent that the curve for emptying of the dextrose meal con-

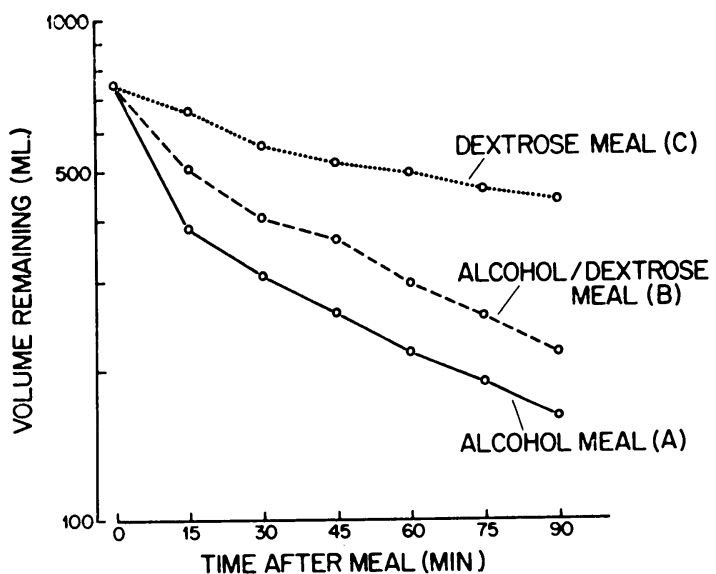

Fig. 2 Log-linear plut of gastric emptying of the three meals. 
formed to an exponential function, and that the curves for the other two meals are exponential after the first 15 minutes. Emptying during the initial 15 minute period was more rapid with these meals than during the remainder of the study period, especially in the case of the ethanol meal. The difference between the ethanol and ethanol-dextrose meals is attributable in large part to the more rapid evacuation of the ethanol meal during the first 15 minutes, for, thereafter, the slopes for emptying of the two meals are similar.

\section{GASTRIC pH}

In response to the dextrose meal, there was profound inhibition of gastric acid secretion, evidenced by a progressive rise in gastric $\mathrm{pH}$ in all subjects. In contrast, gastric $\mathrm{pH}$ fell steadily after the ethanol and ethanol-dextrose meals (Fig. 3). With the two latter meals, mean values for gastric $\mathrm{pH}$ at each time point were almost identical. The differences between the dextrose meal and the other two meals are statistically highly significant $(\mathrm{P}<0 \cdot 01$, Wilcoxon's rank sum test, two tailed) for each time point.

GASTRIC BILE ACID CONCENTRATIONS

These rose significantly after each of the three meals (Fig. 4). Each therefore provoked some regurgitation of duodenal contents. For any given time point, the differences in concentrations between the three meals

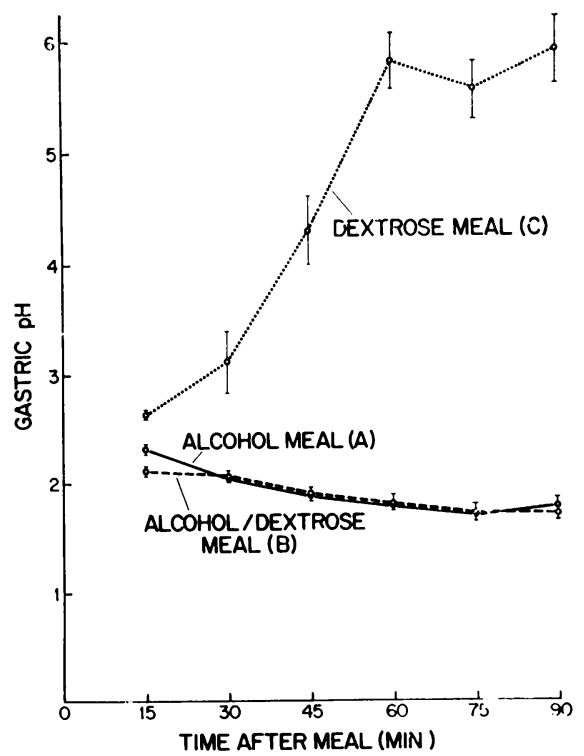

Fig. 3 Serial measurements of gastric $p H$ in response to the three meals. Each point represents the mean and standard error of the mean for nine subjects.

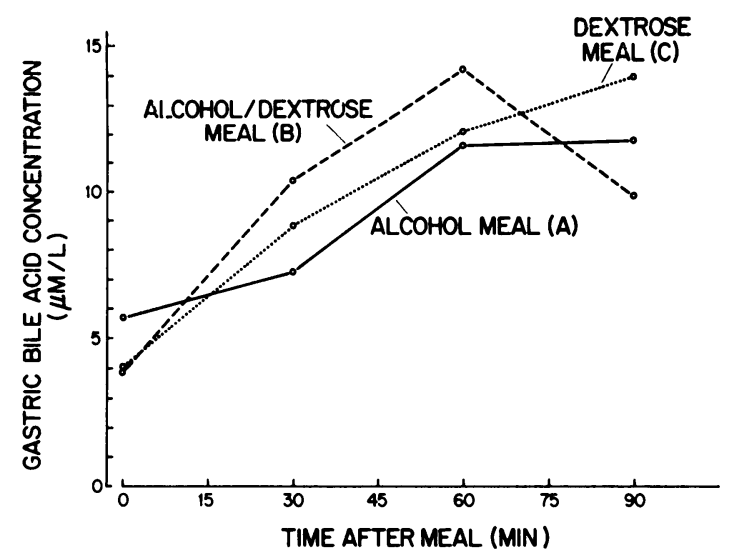

Fig. 4 Serial measurements of gastric bile acid (glycocholic acid and glycochenodeoxycholic acid) concentrations after the three meals. Each point represents the mean for nine subjects. Differences between the meals are not statistically significant.

are not significant. If the total amounts of intragastric bile acids (volume remaining $x$ bile acid concentration) are plotted, differences between the three meals increase but do not reach statistical significance $(P>0 \cdot 1)$.

BLOOD ETHANOL CONCENTRATIONS

These are shown in Fig. 5. Peak mean concentrations (mean $\pm \mathrm{SD}$ ) were $1.04 \pm 0.20$ and $0.31 \pm 0.08 \mathrm{~g} / 1$ and occurred 45 and 75 minutes after administration of the ethanol and ethanol-dextrose meals respectively.

\section{Discussion}

Previous studies designed to examine the influence of ethanol upon emptying of the human stomach have been few. Hunt and Pathak (1960) described slowing of emptying with increasing concentrations of

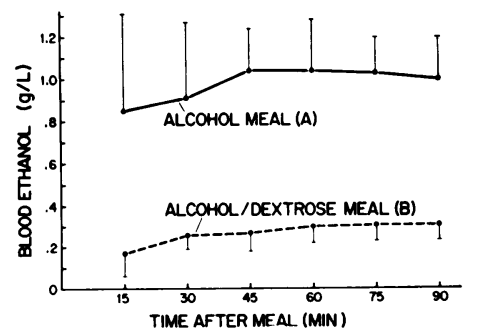

Fig. 5 Serial measurements of blood ethanol after the ethanol and ethanol/dextrose meals. In contrast with the previous figures, each point represents the mean \pm standard deviation. 
ethanol. Cooke $(1970,1972)$ reported that emptying was unaffected by ethanol in concentrations of $6 \mathrm{~g} / 100 \mathrm{ml}$ but slowed at higher concentrations. On the other hand, Harichaux et al. (1970), who studied emptying by a less sensitive and less accurate radiographic technique, observed acceleration of emptying by ethanol in low concentrations, but slowing at higher concentrations.

One of the factors which tends to confound interpretation of studies of gastric emptying is the lack of a universally accepted reference solution against which the effect of other solutions can be compared. Numerous test meal variables, including hydrogen ion concentrations (Hunt and Knox, 1969) osmolality (Hunt and Pathak (1960), fat (Roberts, 1931), amino acids (Thomas and Crider, 1939), and energy density (Hunt and Stubbs, 1975) have been shown to influence the rate of gastric emptying. As ethanol has both osmotic and calorigenic properties, our study was designed to compare emptying of an ethanol meal with that of a meal with identical osmolality, energy density, and hydrogen ion concentration. In the circumstances of the study conditions, the emptying of the ethanol meal was much more rapid than that of a dextrose meal of similar osmolality and energy density. The rate of emptying with the third meal, which contained both ethanol and dextrose, was intermediate between that of the other two solutions, though it approximated more closely to the meal which contained ethanol only. Indeed, when the rates of emptying are plotted semilogarithmically (Fig. 2), it can be seen that the difference between the ethanol and the ethanoldextrose meals is due chiefly to the more rapid emptying of the ethanol meal during the first 15 minutes. Thereafter, the slopes which describe the rate of emptying for these two solutions are similar. It should be noted that emptying of these two solutions after the initial 15-30 minutes conforms to an exponential function, whereas during the initial period it does not.

Several possible reasons for the differences in emptying rates between the three meals require consideration. Firstly, as ethanol is absorbed from the stomach (Hogben et al., 1957; Cooke and Birchall, 1969), it could be argued that the more rapid rate of emptying of the ethanol meal was due to such intragastric absorption rather than to a more rapid rate of delivery of gastric contents to the duodenum. Though possibly contributory, this factor cannot account for the total difference, as the volume of ethanol in the ethanol meal was $80 \mathrm{ml}$, whereas the mean difference between the ethanol and dextrose meals in the volume of gastric contents remaining after 15 minutes was approximately $277 \mathrm{ml}$. Secondly, it is possible that gastric absorption of ethanol might have led to a reduction in osmolality of gastric contents and, secondarily, duodenal contents. Again, it seems unlikely that this factor could account for a major proportion of the difference in emptying rates, particularly as this difference was so striking during the initial 15 minutes' period after administration of the meals. A third possibility, that the relative delay in emptying with the dextrose solution might reflect an increased gastric secretory response to this particular meal, can be excluded with confidence. For, although gastric secretory rates were not measured quantitatively, intragastric $\mathrm{pH}$ fell progressively, indicating active gastric secretion, after the ethanol and ethanol-dextrose meals, whereas it rose sharply and then remained at high levels, indicating rather profound inhibition of secretion, after the dextrose meal (Fig. 3). Inhibition of gastric acid secretion by intraduodenal carbohydrate has been well documented (Day and Komarov, 1939; Sircus 1958, Konturek and Grossman, 1965). However, the magnitude of inhibition which we observed was perhaps greater than might have been anticipated from previously published studies.

A fourth possibility, that relative delay in emptying of the dextrose meal might be due to a larger retrograde flow of duodenal contents after this meal than after the other two meals, merits some consideration. The observation that serial values for intragastric bile acid concentrations after the three meals were similar (Fig. 4), whereas intragastric volumes were substantially greater after the dextrose meal, suggests that a greater degree of duodenogastric reflux might have occurred in response to this latter meal. However, differences between the meals with respect to total intragastric bile acids did not achieve statistical significance. Moreover, bile acid concentrations remained low (less than $5 \mu \mathrm{mol} / \mathrm{l}$ ) throughout the study period after the dextrose meal in four of the nine subjects analysed, yet, in these same four subjects, the dextrose meal emptied much more slowly than the other meals. Although, as delivery of bile to the duodenum is intermittent, the measurement of intragastric bile acids provides an estimate, rather than precise quantification, of duodenogastric reflux, we believe that it is highly unlikely that a greater degree of such reflux was responsible for the slower emptying of the dextrose meal.

Finally, it is possible that the duodenal osmoreceptor mechanism is less sensitive to ethanol than to dextrose. This would appear to be the most likely explanation for the observed differences in emptying rates and is in accord with the observations of Hunt and Pathak (1960) who reported that solutions of ethanol emptied more rapidly than solutions of glucose with similar osmotic activity.

Hunt and Stubbs (1975) described a close rela- 
tionship between the energy density of a meal and its rate of emptying. On the basis of analysis of studies in which emptying rates of carbohydrate and fat meals were measured, it was concluded that the emptying rates for $4 \mathrm{~g}$ of fat and $9 \mathrm{~g}$ of carbohydrate (each equivalent to $36 \mathrm{Kcal}$ ) were the same. Moreover, the relationship between energy density and emptying is carried further by unpublished observations of Fisher and Hunt (quoted by Hunt and Stubbs 1975) that gram for gram, the emptying rates of casein and glucose are the same. In view of these observations, the meals used in our study were designed to be isocaloric. As the emptying rates for the three meals were so markedly different, it is abundantly clear that the relationship between energy density and emptying rate breaks down in the case of ethanol. Teleologically this is not surprising, for, although it is reasonable to postulate the presence in mammals of duodenal receptors responsive to fatty acids, carbohydrates, and amino acids, it seems highly improbable that man would be equipped with a duodenal receptor highly sensitive to ethanol, which, despite its easy manufacture, ready availability, and enormous consumption, could scarcely be considered to be an important natural source of nutrition.

The initial stimulus to this study arose from our observations (Kaufman and Kaye, 1978) that ethanol induces gastro-oesophageal reflux. Our current findings allow a firm conclusion that this effect of ethanol is not due to an impairment of gastric emptying.

This study was supported by a grant from the Distilled Spirits Council of the United States, Inc.; and by Grant RR 109 from the General Research Centers Program of the Division of Research Resources, National Institutes of Health, Bethesda, Maryland, USA.

\section{References}

Bonnichsen, R. K., and Theorell, H. (1951). An enzymatic method for the microdetermination of ethanol. Scandinavian Journal of Clinical and Laboratory Investigation, 3, 58-62.
Cooke, A. R. (1970). The simultaneous emptying and absorption of ethanol from the human stomach. American Journal of Digestive Diseases, 15, 449-454.

Cooke, A. R. (1972). Ethanol and gastric function. (Letter.) Gastroenterology, 62, 501-502.

Cooke, A. R., and Birchall, A. (1969). Absorption of ethanol from the stomach. Gastroenterology, 57, 269-272.

Day, J. J., and Komarov, S. A. (1939). Glucose and gastric secretion. American Journal of Digestive Diseases, 6, 169-175.

Demers, L. M., and Hepner, G. (1976). Radioimmunoassay of bile acids in serum. Clinical Chemistry, 22, 602-606

George, J. D. (1968). New clinical method for measuring the rate of gastric emptying: the double sampling test meal. Gut, 9, 237-242.

Harichaux, P., Capron, J.-P., Lienard, J., and Freville, M. (1970). Influence de l'éthanol sur l'évacuation gastrique. Étude clinique et expérimentale. Lille Médical, 15, 10591065.

Hogan, W. J., Viegas de Andrade, S. R., and Winship, D. H. (1972). Ethanol-induced acute esophageal motor dysfunction. Journal of Applied Physiology, 32, 755-760.

Hogben, C. A. M., Schanker, L. S., Tocco, D. J., and Brodie, B. B. (1957). Absorption of drugs from the stomach. II The human. Journal of Pharmacology and Experimental Therapeutics, 120, 540-545.

Hunt, J. N., and Knox, M. T. (1969). The slowing of gastric emptying by nine acids. Journal of Physiology (London), 201, 161-179.

Hunt, J. N., and Pathak, J. D. (1960). The osmotic effects of some simple molecules and ions on gastric emptying. Journal of Physiology (London), 154, 254-269.

Hunt, J N, and Stubbs, D. F. (1975). The volume and energy content of meals as determinants of gastric emptying. Journal of Physiology (London), 245, 209-225.

Kaufman, S. E., and Kaye, M. D. (1978). Induction of gastro-oesophageal reflux by alcohol Gut, 19, 336-338.

Konturek, S., and Grossman, M. I. (1965). Effect of perfusion of intestinal loops with acid, fat, or dextrose on gastric secretion. Gastroenterology, 49, 481-489.

Roberts, W. M. (1931). The effect of oils on gastric secretion and motility. Quarterly Journal of Medicine, 24, 133-152.

Simmonds, W. J., Korman, M. G., Go, V. L. W., and Hofmann, A. F. (1973). Radioimmunoassay of conjugated cholyl bile acids in serum. Gastroenterology, 65, 705-711.

Sircus, W. (1958). Studies on the mechanisms in the duodenum inhibiting gastric secretion. Quarterly Journal of Experimental Physiology, 43, 114-133.

Thomas, J. E., and Crider, J. O. (1939). Inhibition of gastric motility associated with the presence of products of protein hydrolysis in the upper small intestine. American Journal of Physiology, 126, 28-38. 